(2) Open Access Full Text Article

REVIEW

\title{
Obesity and the development of type 2 diabetes: the effects of fatty tissue inflammation
}

This article was published in the following Dove Press journal:

Diabetes, Metabolic Syndrome and Obesity:Targets and Therapy I5 July 2010

Number of times this article has been viewed

\section{Dara P Schuster \\ Departments of Internal Medicine and Surgery, Divisions of Endocrinology and Metabolism and Gastrointestinal Surgery, The Ohio State University Hospitals and Children's Hospital, Columbus, Ohio, USA}

Correspondence: Dara P Schuster 49I McCampbell Hall, I58I Dodd Drive, Columbus, Ohio 43210, USA

$\mathrm{Tel}+\mathrm{I} 6142920678$

Fax +I 6142921550

Email dara.schuster@osumc.edu

\begin{abstract}
Obesity is a worldwide epidemic with multiple obesity-associated health problems including type 2 diabetes, hypertension, and cardiovascular disease. Adipose tissue serves as a fuel storage depot, but also plays a pivotal role in homeostasis of energy expenditure, appetite regulation, glucose regulation, and immunity. Both genetics and environment play important roles in adipose tissue function and dysfunction. Obesity represents an abnormal accumulation of adipose tissue resulting from chronic overnutrition and reduced physical activity. The nature of this increased accumulation of fat tissue, whether hyperplasia or hypertrophy, local or ectopic, is associated with deleterious perturbations including excess fatty acid secretion, increased production of inflammatory cytokines, and abnormal adipocyte hormone signaling resulting in insulin resistance. In the setting of obesity, insulin resistance and chronic inflammation is postulated to play a role in development of type 2 diabetes and other obesity-related comorbidities including obstructive sleep apnea, hepatic steatosis, polycystic ovarian syndrome, hypertension and cardiovascular disease. Although the exact mechanism of these relationships are complex and not completely understood, the ability to store and limit fatty acid deposition to adipose tissue is a common component to remaining insulin sensitive, controlling the inflammatory cascade and reducing the risk of developing obesity-related comorbidities.
\end{abstract}

Keywords: adipose tissue, inflammatory cascade, adipocyte, insulin resistance, glucose regulation, healthy obese

\section{Introduction}

The epidemic of obesity is worldwide - the World Health Organization statistics from 2005 demonstrated that 400 million people were obese in the world, with a projected increase to 700 million by $2015 .^{1}$ In the USA, the current prevalence of obesity for adult men is $32.2 \%$ and for adult women $35.5 \% .^{2}$ The etiology for the increased rates of obesity has been related to worsening lifestyle, with overnutrition and lack of physical activity. This increase in obesity is a prelude to multiple obesity-associated health problems including type 2 diabetes mellitus (DM), cardiovascular disease (CVD), and hypertension (HTN), and often these diseases occur together. The term "metabolic syndrome" has been used to characterize this clustering of diseases, although the definition of metabolic syndrome has sparked much debate. The strict definition of metabolic syndrome is having 3 or more of the following abnormalities: waist circumference greater than $102 \mathrm{~cm}$ in men and $88 \mathrm{~cm}$ in women; serum triglyceride level of $150 \mathrm{mg} / \mathrm{dL}$ or higher; high-density lipoprotein (HDL) cholesterol level less than $40 \mathrm{mg} / \mathrm{dL}$ in men and $50 \mathrm{mg} / \mathrm{dL}$ in women; blood pressure of 130/85 $\mathrm{mmHg}$ or

submit your manuscript $\mid$ www.dovepress.com 
higher; fasting glucose level of $110 \mathrm{mg} / \mathrm{dL}$ or higher. ${ }^{3}$ The age at which obesity-related comorbidities begin is unclear. Studies have demonstrated higher rates of morbidity and mortality from CVD, stroke, and colorectal cancer in adults with a history of adolescent-onset obesity vs those who were not obese as adolescents. ${ }^{4}$ Whether this worsening of disease is related solely to the duration of obesity, or whether the underlying changes in metabolism and inflammation that characterizes this constellation of comorbidities is the primary issue, is unknown. Therefore, understanding the role of the fat tissue in hormone secretion, inflammation, appetite stimulation, and the pathophysiology of obesityrelated comorbidities will be of key importance in developing treatment and prevention strategies.

\section{Discussion}

\section{Physiological role of adipose tissue in the body}

Adipose tissue serves as the major storage site for fuel, primarily in the form of triglycerides. Mammalian adipose tissue can be divided into brown adipose tissue and white adipose tissue (WAT) with the majority of fat in humans occurring as WAT. Brown adipose tissue is important for regulating heat and non-shivering thermogenesis, and is seen predominately in young and/or hibernating mammals. WAT serves several roles including heat insulation, mechanical cushioning, and fuel storage. ${ }^{5}$ Adipose tissue also acts as a buffer for energy imbalances in the setting of energy excess and storage.

The bulk of adipose tissue is made up of lipid filled adipocytes held together by a framework of collagen fibers. Other cells found within the fat include stromal-vascular cells, leukocytes, macrophages and pre-adipocytes. ${ }^{6-8}$ The white adipose cells have limited vascularity, with blood flow varying based on body weight and nutritional status. In the setting of fasting, blood flow increases to the WAT.

The size of the adipose tissue mass is a function of both adipocyte number and size. ${ }^{6}$ Adipocyte number is controlled by apoptosis/necrosis and through development and differentiation of progenitor cells, preadipocytes. An increase in adipocyte mass can occur with differentiation of pre-adipocytes, as well as with increased lipid deposition within the adipocyte. ${ }^{7,8}$ In humans, there are 2 periods of hyperplastic growth, including the 3rd trimester of pregnancy and early in puberty. However, hyperplastic growth can occur in adulthood. When adipocytes reach a critical size, precursor cells are stimulated to differentiate which results in increase in adipocyte number. Once new adipocytes are formed, which can occur in the setting of long term overfeeding, they remain for life. The mechanism for these signals is not well defined and may be in part genetically determined. In addition, in WAT there are differences in the rates of apoptosis and number and differentiation of progenitor cells between subcutaneous fat depots and visceral fat depots as well as differences in responses to certain stimuli such as tumor necrosis factor-alpha (TNF- $\alpha$ ) on apoptosis and peroxisome proliferator-activated receptor-gamma (PPAR- $\gamma$ ) on proliferation. ${ }^{9}$ Obesity due to hyperplastic cell growth is felt to be more benign with regards to development of metabolic derangements and inflammation than adipocyte hypertrophy in which the fat cell has decreased ability to store triglycerides. ${ }^{10}$

In addition to energy storage, adipose tissue plays an active role in many homeostatic processes including energy expenditure, appetite regulation, and glucose regulation. In addition, fat tissue is critical for thyroid function, immune response, bone health maintenance, reproduction, and blood clotting. These processes are regulated by a variety of hormone pathways and interactions. The adipose tissue is an active endocrine organ secreting free fatty acids, leptin, adiponectin, adipsin, complement factor 3, interlukin-6 (IL-6), TNF- $\alpha$, angiotensinogen, and plasminogen activation inhibitor-1 (PAI-1), among others. Abnormal signaling, deficiency of, or resistance to these hormones have been shown to have deleterious effects. ${ }^{11}$

\section{Genetics of obesity}

The etiology for the increasing incidence of obesity is primarily lifestyle-related overnutrition and reduced physical activity, but susceptibility to obesity is complicated and involves environment influenced by genetics. Studies of twins, adoptees, and families all suggest the existence of genetic factors in human obesity. ${ }^{12,13}$ The heritability of obesity estimated from twin studies is high, ranging between 0.6 and 0.9 , with only slightly lower values in twins raised apart compared with those raised together. ${ }^{13}$ Similarly, in adoptees, the body mass index (BMI) correlates with that of their biologic parents rather than that of their adoptive parents. ${ }^{13}$ Wardle et $\mathrm{al}^{14}$ examining 5000 pairs of twins age 8 to 11 , revealed that genes were responsible for $77 \%$ of the difference in BMI and waist circumference, and environmental influences accounted for $23 \%$ of the differences.

Genetic influence of obesity is related to 2 primary processes: 1. susceptibility to overeating despite normal 
energy requirements, and 2. presence of a normal drive to eat despite low energy requirements. Appetite and the drive to eat may be impacted by several genetically programmed metabolic pathways and this is demonstrated in the specific but rare syndromes of Prader-Willi and leptin deficiency. ${ }^{15}$ Genes may help create the energy imbalance that leads to obesity. In addition to the heritability of weight, metabolic rate, thermic response to food, and spontaneous physical activity are to some extent heritable. ${ }^{16}$ These relationships were illustrated in a study of overfeeding in identical twins. ${ }^{17}$ With respect to body weight, percentage of fat, fat mass, and estimated subcutaneous fat, there was approximately three times more variance among pairs than within pairs, indicating both current weight status and the metabolic processes underlying weight gain have a strong inherited component. The central nervous system provides the feedback control system for integration of energy expenditure and for digestion, absorption, transport, and storage of nutrients, and mobilization and utilization of fuels. Signals regarding alterations in fuel utilization are tightly regulated and come primarily from adipocytes and from the gastrointestinal tract.

In addition, obesity is one of the leading risk factors for the development of DM and most people with DM are overweight or obese. Yet the genetics of DM are also not well defined except for a few of the rarer forms of inherited diabetes such as maturity onset of diabetes of the young (MODY). Furthermore, the link between these 2 complex diseases of fuel metabolism has eluted genomewide searches and associations. In a recent review article, De Silva et $\mathrm{al}^{18}$ summarizes the known 100 common gene variants for predisposition to Type $2 \mathrm{DM}$, obesity, insulin resistance, beta cell function, and elevated cholesterol and their unique and variable impact on fuel metabolism. To identify specific gene defects, Bougnères describes the need to phenotype obesity and DM in order to better identify small genetic variants, as the expression of polymorphisms may be related to environmental changes or triggers that lead to susceptibility to DM and obesity as opposed to monogenic abnormalities. ${ }^{19}$ In this regard, environment plays a key role in genetic expression, minimizing the ability to target specific genes for therapy.

\section{Pathophysiology of increasing adiposity}

When a person is in positive balance, energy is stored in subcutaneous and visceral fat. Obesity is an excess of body fat resulting from an imbalance between energy intake and energy expenditure. Although this statement simplifies the process of obesity, it fails to account for the complicated interaction of variables such as growth hormone, reproductive hormone secretion, and the feedback between energy intake and expenditure, physical activity responses, age, and genetics, as well as psychological issues that may predict eating habits. In addition, it fails to delineate the negative downstream consequences triggered by the body's inability to accommodate the chronic overfed state. Chronic overnutrition promotes a vicious cycle of proinflammatory cytokine secretion, suppression of anti-inflammatory release and macrophage infiltration, leading to metabolic derangements such as insulin resistance and diabetes.

\section{Fatty acids}

One of the negative consequences of chronic overfeeding is elevated levels of free fatty acids. Elevated fatty acids are commonly seen in obesity and DM and lead to diminished whole body glucose utilization and diminished skeletal muscle and cardiac muscle glucose utilization. ${ }^{20}$ In addition, increased levels of circulating fatty acids are inhibitory to beta cells and lead to reduced beta cell function with diminished insulin secretion. ${ }^{21}$

In the setting of increased free fatty acids, the adipose tissue attempts to "keep up" with the fatty acid influx by increasing storage of this excess fuel with both hypertrophy and hyperplasia of the adipose mass. With hypertrophy, increased rates of hypoxia and cell death are seen. The etiology for cellular hypoxia is unclear but is thought to be related to overgrowth of adipose tissue in the setting of failed compensatory angiogenesis as noted by failure of vascular endothelial growth factor (VEGF) expression to increase, leading to decrease adipose tissue blood flow and increased vasoconstriction related to increase expression of angiotensin II. ${ }^{22}$ This is supported by the reduced adipocyte blood flow seen in obese, nondiabetic and DM subjects and the increased macrophages seen in the fat tissue of obese individuals as a result of increased free fatty acids. ${ }^{23,24}$ Mechanistically, in the adipose tissue, induction of innate immune receptors such as Toll-like receptor (TLR) 4 and TLR-2 by the increased free fatty acids can lead to activation of $\mathrm{I} \kappa \mathrm{B} /$ nuclear factor $\kappa$-light-chain-enhancer of activated B cells (NFKB) system and Jun N-terminal kinase (JNK), resulting in an inflammatory response..$^{25,26}$ The subsequent inflammatory response by the adipose tissue stimulates secretion of other pro-inflammatory cytokines, locally and systemically. 


\section{Negative consequences of increasing adiposity \\ Oxidative stress}

Oxidative stress is due to an imbalance between the ability of a biological system to detoxify and the production of reactive oxygen species (ROS) such as peroxides and free radicals. This imbalance can lead to cell damage and apoptosis. Evidence suggests that obesity may induce systemic oxidative stress via oxidative stress in the accumulated adipose tissue, leading to derangements in adipocytokines secretion. ${ }^{27}$ In a series of elegant experiments examining the relationship of obesity and oxidative stress, Furukawa et $\mathrm{al}^{27}$ made the following observations: 1 . in obese, nondiabetic humans, lipid peroxidation, a marker of oxidative stress, as measured by plasma thiobarituric acid reactive substance (TBARS) and urinary 8-epi-prostaglandin-F2 $\alpha$ (8-epi-PGF2 $\alpha$ ), correlated with BMI and waist circumference, and inversely correlated with adiponectin; 2. in obese mice models including KKAy, $\mathrm{DIO}$, and $\mathrm{db} / \mathrm{db}$ mice, lipid peroxidation in plasma as well as in WAT was increased; 3. in KKAy mice, mRNA expression was lower for adiponectin and PPAR $\gamma$ in WAT and higher for expression of proinflammatory markers, PAI- 1 and TNF- $\alpha$, prior to the onset of diabetes, when compared to controls; 4. in mice, augmentation of NADPH oxidase, a principal source of ROS, occurred in WAT but not in liver or skeletal muscle; and 5. in cultured adipocytes, elevated ROS levels were seen in differentiation of 3T3-L1 pre-adipocytes into adipocytes, indicating a role for fat accumulation in ROS production. They concluded that the obese state is characterized by oxidative stress. Oxidative stress in humans has been found to play a role in the development of diabetes, hypertension, and vascular disease and may be a mechanistic link between obesity and the metabolic syndrome..$^{28-30}$

\section{Increased inflammatory markers}

Inflammation appears to be one of the key but complex triggers linked to the metabolic derangements of obesity. Obesity itself represents a chronic inflammatory state, as noted by increased levels of proinflammatory cytokines including IL-1, IL-6, and TNF- $\alpha$, with a downstream cascade that can stimulate liver production of C-reactive protein (CRP) and other cytokine release.The inflammatory response seen locally at the adipose tissue level also includes macrophage infiltration and resistance to hormones such as leptin, and systemically by increased levels of CRP, PAI-1 and fibrinogen, and tissue specific hormone activity such as overexpression of $11 \beta$-hydroxysteroid dehydrogenase
(11ß-HSD). ${ }^{31}$ In conjunction with the concept of obesity being a state of chronic inflammation potentiating the development of insulin resistance and HTN, interest in defining the mechanistic relationship between impaired glucose-insulin metabolism and obesity, and the potential impact of interventions such as physical activity, has been highlighted by several studies. ${ }^{32,33}$

\section{Dysregulated adipocytes hormone signaling}

Adipose tissue plays a significant role in hormone secretion and regulation to maintain metabolic and immune function..$^{34,35}$ In the past decade, anti-inflammatory adipokines (including leptin and adiponectin), along with proinflammatory adipocytokines (including TNF- $\alpha$, IL-6, resistin, and 11 $\beta$-HSD and many others), have all received tremendous attention for their potential role in obesity, glucose homeostasis, insulin resistance, and atherosclerosis, ${ }^{34,35}$ each appearing to play variable roles, locally and systemically, in a redundant system.

Adiponectin, a 244 amino acid peptide solely produced and secreted by adipose tissue, has been reported to improve insulin sensitivity and possibly reduce the risk of DM. ${ }^{36,37}$ Unlike other adipose tissue-derived peptides that are elevated in obesity, adiponectin levels are decreased in obese individuals with insulin resistance, and higher levels of adiponectin are associated with lower risk of DM in older men and women. ${ }^{36,38}$ Thus, the lower adiponectin levels in obese individuals with larger adiposity are paradoxical suggesting that in obese individuals, the adiponectin gene may be down regulated. To complicate this further, adiponectin is secreted differentially within the visceral and subcutaneous fat. In a recent review, Samaras et al ${ }^{39}$ demonstrated depot-specific differences in expression of DM predictors: visceral adipose tissue (VAT) expressed higher levels of complement C3; subcutaneous adipose tissue (SAT) expressed higher levels of retinol-binding protein-4 (RBP4), adiponectin, and leptin. The VAT in DM, expressed higher levels of inflammatory adipokines. Finally, it is well known that interventions that reduce percent adipose mass, weight loss, and aerobic exercise independently increase adiponectin levels with a concomitant improvement in insulin sensitivity. However, the direct role of adiponectin on insulin resistance continues to be examined and may be site specific..$^{37,39-40}$

Leptin, also produced by the adipocytes, circulates at levels proportionate to levels of body fat. It binds to receptors in the hypothalamus, activating signals to inhibit food intake and increase energy expenditure. Leptin affects other hormones, 
both anorectic and orexigenic. In muscle, leptin stimulates free fatty acid oxidation and attenuates insulin-mediated anti-oxidative effects. In adipose tissue, leptin inhibits insulin binding, insulin-mediated glucose transport, lipogenesis, and glycogen synthase activity. In addition, leptin plays a role in areas other than fuel metabolism including fetal growth, puberty, hematopoiesis, and thermogenesis. ${ }^{41}$ Congenital leptin deficiency is rare and it appears that the typical state of obesity in humans is more likely to be related to leptin resistance rather than deficiency. ${ }^{42}$

Other hormones secreted by the adipose tissue include resistin, and primarily by the VAT, visfatin, omentin, and vaspin, are thought to play a role in insulin resistance although their exact functions are unclear. Resistin is elevated in obesity and DM, but it is not thought to play a primary role in the development of insulin resistance.

\section{Insulin resistance}

Obese adults demonstrate reduced glucose disposal, primarily at the level of skeletal muscle (peripheral insulin resistance), as well as impairment in insulin action on nonesterified fatty acid oxidation leading to insulin resistance and abnormal lipolysis. ${ }^{43,44}$ Yet it is unclear whether these abnormalities occur in the setting of acute vs chronic obesity. Polonsky et $\mathrm{al}^{45}$ examined obese, nondiabetic adults and found that insulin secretion rates were significantly higher in the obese group when compared to the normal weight group. Furthermore, there was no difference in insulin clearance or hepatic insulin extraction between the groups. There was a diminished hepatic insulin extraction noted in a subset of the obese group that demonstrated greater degree of hyperinsulinemia. To examine this further, Monti et $\mathrm{al}^{46}$ examined obese children with normoinsulinaemia to characterize early metabolic derangement, and found peripheral insulin resistance when compared to normal weight children, but no significant differences in nonesterified fatty acids response to insulin infusion. Le Stunff et $\mathrm{al}^{47}$ found that the earliest abnormality in glucose metabolism in obese children (those with short duration of obesity) was an abnormal insulin response to a meal stimuli, and that maximal glucose uptake decreased with obesity duration and age. Although evidence exists that whole body, skeletal muscle, and hepatic insulin resistance improves as does hyperglycemia, hyperlipidemia, and HTN with the loss of excess body weight, the mediators of the relationship between glucose dysregulation and weight loss remain unclear. ${ }^{48}$ The mechanism for obesity-induced insulin resistance is related to overproduction of proinflammatory cytokines and hormones that directly and indirectly induce insulin resistance. ${ }^{49,50}$ Retinol-binding protein-4, secreted by the adipose tissue, induces insulin resistance via reduced phosphatidylinosital-3-OH kinase signaling in the muscle and increase expression of phosphenolpyruvate carboxykinase in the liver, along with diminished adiponectin and PPAR- $\alpha$ activity typical for obesity. ${ }^{51}$ Other factors, both systemically and locally, including TNF- $\alpha$, IL-6, monocyte chemoattractant protein-1, and macrophage products play a role in development of insulin resistance in addition to, and through, their inflammatory properties. In this regard, Iozzo ${ }^{10}$ has demonstrated that, although insulin resistance does improve, regional adipose-specific insulin resistance and hypoperfusion does not improve with weight loss, consistent with the hypothesis of irreversible GLUT-4 translocation defects in the adipose tissue, and thus providing a molecular link between obesity and glucose/fat dysregulation. This irreversible change at the level of the fat could be problematic for weight maintenance or regain. So, it appears that one of the earliest negative effects of obesity is the development of insulin resistance.

\section{Metabolic fat distribution}

Total and abdominal adiposity increase the risk for CVD and mortality among women. Increases in total body fat, VAT, and fat deposition in the muscle occur with age and are associated with insulin resistance, dyslipidemia, and risk for DM and CVD. Subcutaneous fat, when compared to visceral fat, is a more active storage depot, is more responsive to the anabolic action of insulin, and demonstrates a greater readiness for proliferation and expansion. ${ }^{9-11}$ Visceral fat is less sensitive to insulin, which provides a ready depot of energy for local organs and less ability for expansion with fuel storage. ${ }^{10}$

Abdominal or central obesity includes fat surrounding the heart and other organs, intestinal mesentery, and retroperitoneum and is believed to be responsible for CVD, possibly related to drainage into the portal system of the liver, exaggerating the metabolic response. However, the relationship between CVD and VAT is not straightforward, as racial and ethnic differences exist. African Americans have greater insulin resistance with less visceral fat when compared to Caucasians. ${ }^{52}$

Observations that DM appears to resolve quickly after Roux-en-Y gastric bypass (RYGB) may be explained by changes in body fat distribution. Using total body magnetic 
resonance imaging (MRI) to assess VAT loss as a result of bariatric surgery, Busetto et $\mathrm{al}^{53}$ concluded that during the initial rapid weight loss period (ie, initial 6 month period), a preferential mobilization of visceral fat, as compared with total and subcutaneous adipose tissue, can occur and this may explain in part the metabolic improvements that can occur early after bariatric surgery with remission of DM, improvement in insulin resistance, blood pressure, and hyperlipidemia. It is postulated that these changes occur due to changes in incretin secretion and interaction with adipose tissue brought about by the bypass of the hormonally active small bowel. As with total body fat, the distribution of body fat between visceral and subcutaneous compartments also has important genetic determinants. ${ }^{12}$

As a component of central adiposity, altered muscle composition, suggestive of increased ectopic fat content, is an important independent marker of insulin resistance in obesity. ${ }^{54}$ In this regard, the ability of the adipose tissue to expand and contain fatty acid deposition is important to maintain insulin sensitivity and reduce the inflammatory response. When the adipocytes can no longer accommodate the excess fuel delivered, overflow from adipocytes to other areas including skeletal muscle, liver, and heart occurs. This ectopic fat deposition can result in deleterious effects including free radical formation during oxidative phosphorylation, intramyocellular triglyceride accumulation, and the production of toxic lipid metabolites such as fatty-acyl CoAs, ceramides and others that can cause oxidative damage and interfere with insulin signaling at these ectopic sites. Within the fat itself, local production of free radicals potentiates lipotoxicity and insulin resistance and provides the trigger for other detrimental hormone cascades. ${ }^{10}$

\section{Physical inactivity}

When we discuss the negative consequences of obesity on glucose and lipid regulation, inflammation, and body fat distribution, we must consider the role of physical inactivity in both development of obesity, and as an independent mediator of metabolic derangements. ${ }^{55}$ Crespo et $\mathrm{al}^{56}$ found that physical activity protected against all-cause mortality, independent of body weight. With regard to ectopic fat deposition, Perseghin et $\mathrm{al}^{57}$ found that habitual physical activity was associated with reduced intrahepatic fat content and Goodpaster ${ }^{54}$ demonstrated that ectopic fat in the thigh muscle correlated to inactivity and insulin resistance. Physical activity has been found to improve insulin resistance and reduce the risk of development of DM and promote lipid oxidation. ${ }^{8,10,57}$
The precise mechanism for these actions is unclear, but it does appear that the majority of benefits of exercise are obtained via its impact on metabolic factors rather than weight loss associated with increase caloric expenditure. Thus, the metabolic derangements seen in the setting of inactivity, and the metabolic improvements brought about by physical activity, provide insight into the pathophysiology of obesity.

\section{Development of obesity comorbidities as characterized by insulin resistance and increase inflammation}

\section{Type 2 diabetes mellitus}

In the pathology of DM, inflammation appears to play a role in disease development and progression. Chronic inflammation in adipose tissue, liver, and skeletal muscle provoke insulin resistance and at the islet, provokes beta cell dysfunction. It is the combination of insulin resistance and beta cell dysfunction that characterizes DM. Various markers of inflammation have been associated with DM including CRP, IL-6, MCP-1, IL-8, and PAI-1. The ability of these inflammatory markers to predict DM appears to be unique to the timing of DM development, with some markers more predictive in impaired glucose tolerance and others in frank diabetes. ${ }^{48,58,59}$ In addition, in the setting of diabetes, multiple other comorbidities are more commonly seen including OSA, hepatic steatosis, HTN, hyperlipidemia, and CAD, indicating a possible common pathway.

\section{Obstructive sleep apnea}

Obstructive sleep apnea (OSA) is commonly seen in the setting of obesity and DM. It is characterized by sleep disordered breathing, with pauses in breathing that result in arousal or desaturation. Sleep disturbance is linked to higher inflammatory biomarkers such as CRP, IL-6, key proinflammatory cytokines in insulin resistance, and DM. ${ }^{60}$ Adipose hormone changes have also been demonstrated in this setting, including a drop in leptin, increased insulin levels, and a decrease in insulin sensitivity. The etiology for this is unclear, but felt to be related to intermittent hypoxemia that may potentiate the inflammatory cascade, triggering systemic inflammation. ${ }^{60,61}$ In this regard, studies demonstrate improved glucose control and reduced insulin resistance with treatment of OSA.

\section{Hepatic steatosis}

This condition is highly correlated with DM, obesity, insulin resistance, and hyperlipidemia. Non-alcoholic 
fatty liver disease (NAFLD) is a common manifestation of hepatic insulin resistance. One study showed that NAFLD is associated with insulin resistance even in patients with normal glucose tolerance tests. Adipose tissue lipolytic activity is increased in NAFLD and results in an increase in the rate of fatty acid release into plasma throughout the day. This continual excess in fatty acid flux supports the hypothesis that adipose insulin resistance is involved in the pathogenesis of hepatic steatosis and contributes to the metabolic complications associated with NAFLD. ${ }^{62}$ In addition, obesity leads to infiltration of adipose tissue by macrophages that produce cytokines such as IL-6, which contribute to insulin resistance and promote a downstream effect of increased hepatic CRP production.

\section{Polycystic ovarian disease}

Polycystic ovarian disease (PCOS) is commonly accompanied by hyperandrogenism and hyperinsulinemia. Although the exact mechanism for this relationship is unclear, it is postulated that high circulating levels of insulin play a role in ovarian cyst development due to the anabolic effect of insulin at the IGF receptors found on the ovaries. Up to $30 \%$ of women with polycystic ovarian disease are overweight/ obese. Obesity can worsen the picture of PCOS by increasing insulin resistance, DM, and metabolic syndrome, but the increased degree of obesity itself has only a modest impact on disease development. ${ }^{63}$

\section{Hypertension}

When examining the relationship of obesity to HTN, elevated blood pressure occurred more than 9 times more frequently in the obese group. ${ }^{64}$ The incidence of HTN is two fold higher in subjects with DM when compared to subjects without. ${ }^{65}$ The exact mechanism for this relationship is unclear. Activation of the sympathetic nervous system leading to sodium retention and resetting of volume status appears to be an early change in the setting of obesity. Plasma renin activity, angiotensinogen, angiotensin II, and aldosterone are increased, and leptin, endothelin 1, and other neuropeptides also play a role. ${ }^{66}$ Endothelin 1, an endothelium-derived vasoconstrictor, is associated with increased vascular tone, development of HTN, and atherosclerosis. In linking endothelin 1 to the metabolic syndrome, hyperglycemia increases endothelin 1 expression in cell culture through protein kinase $\mathrm{C}$ (PKC); and in endothelial cells, insulin increases endothelin 1, ${ }^{68}$ indicating a mechanistic relationship between obesity, insulin resistance, and HTN.
Hyperinsulinemia appears to play a role in the development of HTN; possibly related to changes in angiotensin II and sodium retention in obese subjects. ${ }^{69}$

\section{Hyperlipidemia}

The classic dyslipidemic pattern of the metabolic syndrome is characterized by elevated serum low-density lipoproteincholesterol and triglycerides and reduced high-density lipoproteins. This pattern is associated with enhanced tendency to LDL oxidation, and a reduction in the ability of HDL to promote cellular cholesterol efflux. Central fat distribution, possibly through its impact on insulin levels, may be the mediating variable between obesity and lipids. Increased free fatty acids, produced by lipolysis by the visceral adipocytes, and hyperinsulinemia, promotes hepatic triglyceride and LDL-cholesterol synthesis. ${ }^{70,71}$ Weight reduction improves this profile.

\section{Cardiovascular disease}

Obesity correlates strongly with traditional risk factors of CAD including DM, HTN, hyperlipidemia, and OSA. Unifying these comorbidities is the back drop of chronic inflammation. Obesity, and central obesity in particular, is associated with increased inflammatory markers such as CRP, IL-6, and PAI-1 and there may be genetic susceptibility to oxidative stress. ${ }^{72-74}$ This inflammatory state promotes increased oxidative stress and endothelial dysfunction that in turn promotes atherosclerosis, made worse by hyperglycemia. Endothelial dysfunction is characterized by diminished production of nitric oxide and other vasoprotective factors and/or increased production of vasoconstrictors and proinflammatory factors such as angiotensin II, endothelin 1 and ROS. ${ }^{75}$ The damaged endothelial surface is a stimulant for mononuclear cell infiltration for repair, and the abnormal lipid oxidation results in development of fatty streaks and vulnerable plaques. ${ }^{76}$ In the setting of DM, an early marker of inflammation is the release of monocyte chemoattractant protein (MCP)-1 and macrophage migration inhibition factor (MIF) in vascular endothelium and adipose tissue which potentiates vascular disease. ${ }^{74,76-78}$

\section{The healthy obese}

Although obesity is linked to many comorbidities as described above, it is most likely not a direct causal relationship. In this regard, Khittle et al ${ }^{79}$ found that approximately $20 \%$ of obese individuals do not have metabolic abnormalities. The "healthy obese" appear to have less clustering of CVD risk 
factors. What determines healthy obesity vs unhealthy obesity is unknown. In a study by Stefan et $\mathrm{al}^{80}$ subjects were divided into 3 groups - normal weight, obese-insulin sensitive, and obese-insulin resistant - and cardiovascular risk factors were examined. They found that the obese-insulin sensitive group had intimal medial thicknesses similar to that seen in the normal weight group, and when compared to the insulin resistant group, had less skeletal muscle fat, less hepatic fat deposits, and lower intimal-media thickness of the common carotid artery, giving them a more favorable risk profile despite similar weights. Thus, it appears that in some limited circumstances, the adipose tissue has a greater ability to expand without the associated metabolic stress that triggers pro-inflammatory cytokine production and downstream effects such as insulin resistance. Mitigating factors such as physical activity and genetic background may play a key role to the health of this small cohort of the obese population, and serve to remind us of the need for further understanding and possibly phenotyping of the obese patient.

\section{Conclusion}

Obesity is an abnormal state of chronic overnutrition and reduced physical activity with genetic predisposition playing a role in worsening consequences and development of co-morbid conditions. Obesity is commonly associated with increased production of proinflammatory cytokines, insulin resistance, and changes in body fat distribution. In addition, there are multiple, complex, redundant biochemical pathways that have an impact locally and systemically to provoke and potentiate insulin resistance and chronic inflammation, which in turn promote further downstream perturbations such as DM, OSA, HTN and CVD. Thus, the ability to store and limit fatty acid deposition to adipose tissue is a key component in remaining insulin sensitive, controlling the inflammatory cascade, and reducing the risk of developing obesity-related comorbidities such as DM.

\section{Disclosure}

The author reports no conflicts of interest in this work

\section{References}

1. World Health Organization Fact Sheet for world wide prevalence of obesity. 2006 September. Available from: http://www.who.int/ mediacentre/factsheets/fs311/en/index.html

2. Flegal KM, Carroll MD, Ogden CL, Curtin LR. Prevalence and trends in obesity among US adults, 1999-2008. JAMA. 2010;303:235-241.

3. Executive summary of the third report of the National Cholesterol Education Program (NCEP) expert panel on detection, evaluation, and treatment of high blood cholesterol in adults (Adult Treatment Panel III). JAMA. 2001;285:2486-2497.
4. Must A, Jacques PF, Dallal GI, Pajema CJ, Dietz W. Long-term morbidity and mortality of overweight adolescents. A follow-up of the Harvard Growth Study of 1922 to 1935. N Engl Med. 1992;327: $1350-1355$.

5. Rodeheffer MS, Birsoy K, Friedman JM. Identification of white adipocyte progenitor cells in vivo. Cell. 2008;135:240-249.

6. Tang W, Zeve D, Suh J, et al. White fat progenitior cells reside in the adipose vasculature. Science. 2008;322:583-586.

7. Knittle J, Timmers K, Ginsberg-Fellner F, Brown RE, Katz DP. The growth of adipose tissue in children and adolescents. J Clin Invest. 1979;63:239-246

8. Ailhaud G. Adipose cell differentiation in culture. Mol Cell Biochem. 1982;49:17-31.

9. Adams M, Montague CT, Prins JB, et al. Activators of peroxisome proliferator-activated receptor gamma have depot-specific effects on human preadipocyte differentiation. J Clin Invest. 1997;100:3149-3153.

10. Iozzo P. Viewpoints on the way to the consensus session. Where does insulin resistance start? The adipose tissue. Diabetes Care. 2009;32 Supp1 2:S168-S173.

11. Kissebah AH, Vydelingum N, Murray M, et al. Relation of body fat distribution to metabolic complications of obesity. J Clin Endocrinol Metab. 1982;54:254-260.

12. Bouchard C, Despres JP, Mauriege P. Genetic and nongenetic determinants of regional fat distribution. Endocr Rev. 1993;14:72-93.

13. Stunkard, AJ, Sorensen, TI, Hanis C, et al. An adoption study of human obesity. N Engl J Med. 1986;314:193-198.

14. Wardle J, Carnell S, Haworth CMA, Plomin R. Evidence for a strong genetic influence on childhood adiposity despite the force of the obesogenic environment. Am J Clin Nutr. 2008;87:398-404.

15. Woods SC, Seeley RJ, Porte D Jr. Signals that regulate food intake and energy homeostasis. Science. 1998;280:1378-1383.

16. Fontaine, E, Savard, R, Tremblay, A, Despres, JP. Resting metabolic rate in monozygotic and dizygotic twins. Acta Genet Med Gemellol (Roma). 1985;34:41.

17. Bouchard C, Tremblay A, Despres JP, et al. The response to long-term overfeeding in identical twins. N Engl J Med. 1990;322:1477.

18. De Silva NM, Frayling TM. Novel biological insights emerging from genetic studies of type 2 diabetes and related metabolic traits. Curr Opin Lipidol. 2010;21:44-50.

19. Bougnères P. Genetics of obesity and type 2 diabetes tracking pathogenic traits during the predisease period. Diabetes. 2002;51 Suppl 3:S295-S303.

20. Randle PJ. Regulatory interactions between lipids and carbohydrates: the glucose fatty acid cycle after 35 years. Diabetes Metab Rev. 1998;14:263-283.

21. Oprescu AI, Bikopoulos G, Naassan A, et al. Free fatty acid induced reduction in glucose-stimulated insulin secretion: evidence for a role of oxidative stress in vitro and in vivo. Diabetes. 2007;56:2927-2937.

22. Ye J. Emerging role of adipose tissue hypoxia in obesity and insulin resistance Int J Obes. 2009;33:54-66.

23. Lumeng CN, Deyoung SM, Bodzin JL, Saltiel AR. Increased inflammatory properties of adipose tissue macrophages recruited during diet-induced obesity. Diabetes. 2007;56:16-23.

24. Cancello R, Henegar C, Viguerie N, et al. Reduction of macrophage insulin resistance and adipose tissue infiltration and chemoattractant gene expression changes in white adipose tissue of morbidly obese subjects after surgery-induced weight loss. Diabetes. 2005;54:2277-2286.

25. Song MJ, Kim KH, Yoon JM, Kim JB. Activation of Toll-like receptor 4 is associated with insulin resistance in adipocytes. Biochem Biophys Res Commun. 2006;346:739-745.

26. Karalis KP, Giannogonas P, Kodela E, Koutmani Y, Zoumakis M, Teli T. Mechanisms of obesity and related pathology: linking immune responses to metabolic stress. FEBS. 2009;276:5747-5754.

27. Furukawa S, Fujita T, Shimabukuro M, et al. Increased oxidative stress in obesity and its impact on metabolic syndrome. J Clin Invest. 2004; 114:1752-1761. 
28. Brownlee M. Biochemistry and molecular cell biology of diabetic complications. Nature. 2001;414:813-820.

29. Nakazono K, Watanabe N, Sasaki J, Sato T, Inoue M. Does superoxide underlie the pathogenesis of hypertension? Proc Natl Acad Sci US A. 1991;88:10045-10048.

30. Ohara Y, Peterson, TE, Harrison DG. Hypercholesterolemia increases endothelial superoxide anion production. J Clin Invest. 1993; 91:2546-2551.

31. Valsamakis G, Anwar A, Tomlinson JW, et al. 11beta-hydroxysteroid dehydrogenase type 1 activity in lean and obese males with type 2 diabetes mellitus. J Clin Endocrinol Metab. 2004;89:4755-4761.

32. Long SD, O’Brien K, MacDonald KG Jr, et al. Weight loss in severely obese subjects prevents the progression of impaired glucose tolerance to type II diabetes. A longitudinal interventional study. Diabetes Care. 1994; 17:372-375.

33. Dixon JB, Dixon AF, O'Brien PE. Improvements in insulin sensitivity and beta-cell function (HOMA) with weight loss in the severely obese. Homeostatic model assessment. Diabet Med. 2003;20: 127-134.

34. Engeli S, Feldpaussch M, Gorzelniak K, et al. Association between adiponectin and mediators of inflammation in obese women. Diabetes. 2003;52;942-947.

35. Straczkowski MA, Kowalska I, Stepien A, Dziena-Straczkowska S, Straczkowska M, Kinalska I. Plasma - soluble tumor necrosis factor alpha-receptors level in lean, nondiabetic offspring of type 2 diabetic subjects. Diabetes Care. 2002;25;1824-1828.

36. Sprangler J, Kroke A, Mohlig M, et al. Adiponectin and protection against type 2 diabetes. Lancet. 2003;361:226-228.

37. Khalili P, Flyvbjerg A, Frystyk J, et al. Total adiponectin does not predict cardiovascular events in middle-aged men in a prospective, long-term follow-up study. Diabetes Metab. 2010;36:137-43.

38. Krakoff J, Funahaser T. Stenhouwer CDA, et al. Inflammatory markers, adiponectin and the risk of type 2 diabetes in the Pima Indians. Diabetes Care. 2003;26:1745-1751.

39. Samaras K, Botelho NK, Chisholm DJ, Lord RV. Subcutaneous and visceral adipose tissue gene expression of serum adipokines that predict type 2 diabetes. Obesity. 2010;18:884-889.

40. Viljanen AP, Lautamäki R, Järvisalo M, et al. Effects of weight loss on visceral and abdominal subcutaneous adipose tissue blood-flow and insulin-mediated glucose uptake in healthy obese subjects. Ann Med. 2009;41:152-160.

41. Margetic S, Gazzola C, Pegg GG, Hill RA. Leptin: a review of its peripheral actions and interactions. Int J Obes. 2002;26:1407-1433.

42. Considine, RV, Sinha, MK, Heiman, ML, et al. Serum immunoreactiveleptin concentrations in normal-weight and obese humans. $N$ Engl J Med. 1996;334:292-295.

43. Del Prato S, Enzi G, de Kreutzenberg SV, et al. Insulin regulation of glucose and lipid metabolism in massive obesity. Diabetologia. 1990;33:228-236.

44. Lillioja S, Foley J, Bogardus C, Mott D, Howard BV. Free fatty acid metabolism and obesity in Man: in vivo and in vitro comparisons. Metabolism. 1986;35:505-514.

45. Polonsky KS, Given BD, Lirsch L, et al. Quantitative study of insulin secretion and clearance in normal and obese subjects. J Clin Invest. 1988;81:435-441.

46. Monti LD, Brambilla P, Stefani I, et al. Insulin regulation of glucose turnover and lipid levels in obese children with fasting normoinsulinaemia. Diabetologia. 1995;38:739-747.

47. LeStunff C, Bourgeres P. Early changes in postprandial insulin secretion, not in insulin sensitivity, characterize juvenile obesity. Diabetes. 1994;43:696-702.

48. Lee CC, Adler AI, Sandhu MS, et al. Association of C-reactive protein with type 2 diabetes: prospective analysis and meta-analysis. Diabetologia. 2009;52:1040-1047.

49. Kahn SE, Hull RL, Utzschneider KM. Mechanisms linking obesity to insulin resistance and type 2 diabetes. Nature. 2006;444:840-846.
50. Shoelson SE, Lee J, Goldfine AB. Inflammation and insulin resistance. J Clin Invest. 2006;116;1793-1801.

51. Yang Q, Graham TE, Mody N, et al. Serum retinol binding protein 4 contributes to insulin resistance in obesity and type 2 diabetes. Nature. $2005 ; 436: 356-362$.

52. Lovejoy JC, Bretonne JA, Klemperer M, Tulley R. Abdominal fat distribution and metabolic risk factors: Effects of race. Metabolism. 1996;45:1119-1124.

53. Busetto L, Tregnaghi A, Bussolotto M, et al. Visceral fat loss evaluated by total body magnetic resonance imaging in obese women operated with laparoscopic adjustable silicone gastric banding. Int J Obes. 2000 ; 24:60-69.

54. Goodpaster BH. Subcutaneous abdominal fat and thigh muscle composition predict insulin sensitivity independently of visceral fat. Diabetes. 1997;46:1579-85.

55. Blair SN. 1993 C.H. McCloy Research Lecture: physical activity, physical fitness, and health. Res Q Exerc Sport. 1993;64:365-376.

56. Crespo CJ, Palmieri MRC, Perdomo RP, et al. The relationship of physical activity and body weight with all-cause mortality: Results from The Puerto Rico Heart Health Program. Ann Epidemiol. 2002;12:543-552.

57. Perseghin G, Lattuada G, De Cobelli F, et al. Habitual physical activity is associated with intrahepatic fat content in humans. Diabetes Care. 2007;30:683-688.

58. Herder C, Baumert J, Thorand B, et al. 2006 Chemokines as risk factors for type 2 diabetes: results from the MONICA/KORA Augsburg study, 1984-2002. Diabetologia. 2002;49:921-929.

59. Rosen P, Nawroth PP, King G, Moller W, Tritschler HJ, Packer L. The role of oxidative stress in the onset and progression of diabetes and its complications: a summary of a Congress Series sponsored by UNESCO-MCBN, the American Diabetes Association and the German Diabetes Society. Diabetes Metab Res Rev. 2001;17:189-212.

60. Suarez EC. Self-reported symptoms of sleep disturbance and inflammation, coagulation, insulin resistance and psychosocial distress: evidence for gender disparity. Brain Behave Immun. 2008;22: 960-968.

61. Meslier N, Gagnadoux P, Giraud C, et al. Impaired glucose-insulin metabolism in males with obstructive sleep apnea syndrome. Eur Respir J. 2003;22:156-160.

62. Fabbrini E, deHaseth D, Deivanayagam D, Mohammed S, Vitola BE, Klein S. Alterations in fatty acid kinetics in obese adolescents with increased intrahepatic triglyceride content. Obesity. 2008;171: 25-29.

63. Yildiz BO, Knochenhauer ES, Azziz R, Impact of obesity on the risk for polycystic ovary syndrome. J Clin Endocrinol Metab. 2008;93: $162-168$.

64. Lauer RM, Connor WE, Leaverton PE, et al. Coronary heart disease risk factors in school children: the Muscatine study. J Pediatr. 1975;86: 697-706.

65. Sowers JR. Recommendation for special populations: diabetes mellitus and the metabolic syndrome. Am J Hypertens. 2003;153: $41 \mathrm{~S}-45 \mathrm{~S}$.

66. Kotsis V, Stabouli S, Papakatsika S, Rizos Z, Parati G. Mechanisms of obesity-induced hypertension. Hypertens Res. 2010;33:386-393.

67. Park JY, Takahara N, Gabriele A, et al. Induction of endothelin-1 expression by glucose: an effect of protein kinase $\mathrm{C}$ activation. Diabetes. 2000;49:1239-1248.

68. Oliver FJ, de la Rubia G, Feener EP, et al. Stimulation of endothelin-1 gene expression by insulin in endothelial cells. J Biol Chem. 1991; 266:23251-23256.

69. Finta KM, Rocchini AP, Moorehead C. Key J, Katch V. Urine Sodium excretion in response to an oral glucose tolerance test in obese and nonobese adolescents. Pediatrics. 1992;90:442-446.

70. Steinberger J, Moorehead C, Katch V, Rocchini AP. Relationship between insulin resistance and abnormal lipid profile in obese adolescents. J Pediatr. 1995;126:690-695. 
71. Caprio S, Hyman LD, Limb C, et al. Central adiposity and its metabolic correlates in obese adolescent girls. Am J Physiol. 1995;269: E118-E126.

72. Shimomura I, Funahashi T, Takahashi M, et al. Enhanced expression of PAI-1 in visceral fat: possible contributor to vascular disease in obesity. Nat Med. 1996;2:800-803.

73. Eriksson P, Reynisdottir S, Lonnqvist F, Stemme V, Hamsten A, Arner P. Adipose tissue secretion of plasminogen activetor inhibitor-1 in non-obese and obese individuals. Diabetologia. 1998;41:65-71.

74. Shinozaki K, Kashiwagi A, Masada M, et al. Molecular mechanisms of impaired endothelial function associated with insulin resistance. Curr Drug Targets Cardiovasc Haematol Disord. 2004;4:1-11.

75. Wong WT, Wong SL, Tian XY, Huang Y. Endothelial dysfunction: the common consequence in diabetes and hypertension. J Cardiovasc Pharmacol. 2010;55:300-307.
76. Sjoholm A, Nystrom T. Endothelial inflammation in insulin resistance. Lancet. 2005;365:610-612.

77. Ballantyne CM, Nambi V. Markers of inflammation and their clinical significance. Atheroscler Suppl. 2005;6:21-29.

78. Christiansen T, Richelsen B, Bruun JM. Monocyte chemoattractant protein-1 is produced in isolated adipocytes, associated with adiposity and reduced after weight loss in morbid obese subjects. Int $J$ Obes. 2005;29:146-150.

79. Knittle JL, Ginsberg-Fellner F, Brown RE. Adipose tissue development in man. Am J Clin Nutr. 1977;30:762-766.

80. Stefan N, Kantartzis K, Machann J, et al. Identification and characterization of metabolically benign obesity in humans. Arch Intern Med. 2008;168:1609-1616.

\section{Publish your work in this journal}

Diabetes, Metabolic Syndrome and Obesity: Targets and Therapy is an international, peer-reviewed open-access journal committed to the rapid publication of the latest laboratory and clinical findings in the fields of diabetes, metabolic syndrome and obesity research. Original research, review, case reports, hypothesis formation, expert opinion and commentaries are all considered for publication. The manuscript management system is completely online and includes a very quick and fair peer-review system, which is all easy to use. Visit http://www.dovepress.com/testimonials.php to read real quotes from published authors.

Submit your manuscript here: http://www.dovepress.com/diabetes-metabolic-syndrome-and-obesity-targets-and-therapy-journal 